\title{
A produção de experiências ativas no ensino de música: reflexões \\ a partir de John Dewey
}

\section{Márlon SouzaVieira}

SM E - PM RJ - Prefeitura M unicipal do Rio de Janeiro

marlonsvieira@gmail.com

M estre em M úsica, UNE SP, Sâo Paulo

D ocente da Pós $G$ raduação em A rtes, U G B 


\section{Resumo}

E ste trabalho trata de uma reflexão que busca um aprofundamento sobre o processo de criação a partir do ensino de música na escola relacionado com os pensamentos considerados pelo filósofo e educador John $D$ ewey. Percebendo que através do ensino de música são promovidos elementos essenciais que provocam experiências ativas no processo de aprendizagem, tanto por parte do professor como do aluno, buscou-se compreender as importantes contribuições que essas experiências podem trazer tanto para o ambiente escolar como para aos indivíduos que dela fazem parte. Procurou-se trazer considerações essenciais apoiado em D ewey, com vistas a dialogar com influência à criatividade e à experiência - fenômeno esse que ocorre no espaço educacional e que ele chamou de pragmatismo. Integram ao referencial basilar desta pesquisa bibliográfica os seguintes autores: B eyer e Kebach (2012), C arneiro \& D odge (2007), Penna (2008) e Swanwick (2003); ainda agregam a esta investigação outros autores complementares. 0 estudo tem como objetivo principal refletir sobre o conceito de experiência com base em D ewey, considerando a importância desse conceito na escola, principalmente, no processo ensino aprendizagem em educação musical. A importância da ampliação de conceitos relacionados ao processo de criação, dentro da perspectiva da educação musical, em que culmina em experiência pessoal e interpessoal, torna a investigação deste processo relevante.

Palavras-chave: Ensino de M úsica. Pragmatismo. Experiência. A mbiente escolar. John D ewey. 


\section{Abstract}

This work deals with a reflection that seeks a deepening of the process of creation from the teaching of music in the school related to the thoughts considered by the philosopher and educator John Dewey. Realizing that through teaching music is promoted essential elements that provoke active experiences in the learning process, both by the teacher and the student he sought to understand the important contributions that these experiences can bring both to the school environment and to the individuals who are part of it. It was sought to bring essential considerations supported D ewey, in order to dialogue with influence in creativity and experience - the phenomenon occurs in the educational space and that he called pragmatism. The following authors include: Beyer and Kebach (2012), Ram \& D odge (2007), Penna (2008) and Swanwick (2003); This research still aggregate other complementary authors. The study aims to reflect on the concept of Dewey-based experience considering the importance of this concept in the school principally in the teaching learning process in musical education. The importance of extending concepts related to the creation process, within the perspective of musical education, in which it culminates in personal and interpersonal experience, makes the relevant investigation of this process.

K eywords: M usic teaching. Pragmatism. Experience. School environment. John D ewey. 


\section{Introdução}

O desenvolvimento da humanidade sempre foi carregado de símbolos e signos que sempre contribuíram para a ampliação de linguagens comunicativas. $N$ esse contexto, consideramos a música como elemento importante nesse processo, mesmo porque, sempre fez parte ativa na vida das pessoas. Ela está vinculada a outras formas de arte desde a antiguidade, dando visibilidade aos processos de transformação da trajetória humana. Segundo Swanwick: "a música é uma forma de discurso tão antiga quanto a raça humana, um meio no qual as ideias acerca de nós mesmos e dos outros são articuladas em formas sonoras" (SWANWICK, 2010, p.18). Já de acordo com Schafer (2011, p.175), "a música é, sobretudo, nada mais que uma coleção dos mais excitantes sons concebidos e produzidos pelas sucessivas operações de pessoas [...]”. Portanto, os sons envolvem nossa mente, participando de um processo de empoderamento do ser que, normalmente, resultam em experiências idiossincráticas.

Também vale ressaltar que o ensino de música tem relação direta com a ludicidade. E m ambiente escolar, sempre há momentos em que o ensino de música se dá por meio de brincadeiras e jogos musicais. $N$ esse cenário, ponderamos que o brincar também possui primazia no processo de desenvolvimento da humanidade que, segundo Carneiro, "é a primeira e mais efetiva experiência em nosso aprendizado como seres humanos" (CARNEIRO; DODGE, 2007, p.10).

Carneiro (2007, p.29) ainda relaciona os termos "brincar" e "atividade lúdica" como sinônimo de "jogar".

[...] há uma grande dificuldade em se conceituar o brincar, pois não existe entre os especialistas consenso a respeito do assunto. A maior parte dos estudiosos prefere usar uma expressão mais ampla - atividade lúdica -, que acaba sendo sinônimo de jogar. (CARNEIRO; DODGE, p.29, 2007)

T endo em vista as breves proposições expostas até aqui, é possível considerar o problema por meio da seguinte questão: como melhor compreender os benefícios das atividades criativas em aula de música que, em todos os momentos, são produtoras de experiências ativas para com as pessoas envolvidas? 
N esse sentido, o objetivo geral desse trabalho é refletir por meio de Dewey sobre a formação de experiências ativas no espaço educacional, considerando o processo de ensino aprendizagem no âmbito da educação musical, buscando avaliar os benefícios e contribuições que possam existir desse fenômeno. A lguns trabalhos acadêmicos já fazem a articulação de $D$ ewey com o componente curricular A rte; dentre esses, chamounos atenção: "A contribuição de John Dewey ao ensino da arte no Brasil" (ANDRADE; CUNHA, 2016) e "A atualidade De John Dewey para a educação: mais arte, não menos" (CUNHA, 2015). Nesse panorama, ponderamos que, estando o processo ensino-aprendizagem integrado às crianças em ambiente escolar, a contribuição obtida será múltipla e disparadora para experiências ativas.

Refletimos que é na escola que novos elementos podem ser desenvolvidos para uma aprendizagem efetiva. Encontramos conexão com Bittencourt por meio de Penna (2008) “ [...] a escola como ponto de partida torna-se uma questão teórico-metodológica que possibilita investir de maneira inovadora e que fornece condições de incluir toda uma série de novos personagens [...]”. (BITTENCOURT, 2003, p.38). Todo esse processo, D ewey conceberá como experiência singular, a partir do ponto em que todo 0 caminho percorrido na interação professor-aluno; idealizará, por meio da execução, concepções de experiência do mundo real.

D essa forma, ajuizamos que sim, a experiência alcançada a partir do ensino de música na escola se faz relevante, na medida que os resultados investigatórios são favoráveis à aprendizagem escolar e provocam experiências singulares e coletivas, ativas e estéticas.

\section{John Dewey e o pragmatismo no processo de ensino-aprendizagem}

John D ewey nasceu nos E stados U nidos da A mérica, em 1859, e doutorou-se em 1884 com uma tese sobre o filósofo Immanuel Kant. Ele iniciou sua carreira profissional como professor na Pensilvânia e em Vermont. Segundo W estbrook

John Dewey foi o filósofo norte-americano mais importante da primeira metade do século $X X$. Sua carreira cobre a vida de três gerações e sua voz pôde ser ouvida no meio das controvérsias culturais dos E stados U nidos (e do estrangeiro) desde a década de 1890, até sua 
morte em 1952, quando completara 92 anos de idade.

(WESTBRO O K; TEIXEIRA, 2010, p. 11)

No entanto, foi na Universidade de M ichigan onde se deu a gênese do seu grande legado; período em que conheceu as ideias de W illiam James, um dos fundadores da psicologia moderna e importante filósofo ligado ao pragmatismo. Foi então que, todo o pensamento educacional filosófico $D$ eweyano assumiu os princípios do pragmatismo ${ }^{1}$.

Para entendimento dessa nova concepção, faz-se necessário perceber que 0 pragmatismo de $D$ ewey se trata de uma crítica à filosofia tradicional - àquela defendida pelos pensadores clássicos². As relações pedagógicas a partir dessa filosofia são unidirecionais, ou seja, do professor para o aluno, sendo este apenas um receptáculo do saber. Já para Dewey, a relação professor-aluno deve ser fundamentada a partir do conceito reflexivo, em que nada está pré-estabelecido ou estável, porém, em movimento constante, de forma que, a partir de um determinado problema se elabora hipóteses e se levante ideias com a finalidade de se chegar, ou não, a algum resultado. Para ele, a aprendizagem ocorre:

[...] mediante 0 enfrentamento de situações problemáticas que surgem no curso das atividades que merecem seu interesse. 0 pensamento constitui, para todos, instrumento destinado a resolver os problemas da experiência e o conhecimento é a acumulação de sabedoria que gera a resolução desses problemas. (WEST BRO O K; TEIXEIRA, 2010, p. 15)

A inda sobre a educação, D ewey considera que:

U ma educação eficaz requer que o educador explore as tendências e os interesses para orientar 0 educador até 0 ápice em todas as matérias, sejam elas científicas, históricas ou artísticas. (WESTBROOK; TEIXEIRA, 2010, p. 17)

D esse modo, podemos refletir que o pragmatismo se dá quando o aprendizado ocorre a partir da execução e da experimentação do pensamento: a experiência prática de

\footnotetext{
${ }^{1}$ Trecho resumido do perfil publicado em 2010 pelo Ministério da Educação: "Coleção de Educadores John Dewey". 2 Sócrates, P latão e A ristóteles são os mais conhecidos pensadores da filosofia tradicional. Juntos formam o tripé do período clássico, são considerados os formuladores de teorias sobre o mundo e sobre o homem.
} 
se lidar com o objeto a ser investigado reflete em aprendizado, transformando essa experiência em conceitos, pensamentos e ideias que permitem trabalhar com outras experiências.

Segundo Dewey (2010, p. 109), "A experiência ocorre continuamente, porque a interação do ser vivo com as modificações ambientais está envolvida no próprio processo de viver".

N esse panorama, temos, até os dias atuais, conceitos sugeridos por D ewey: "pensamento reflexivo", "professor reflexivo", "educação significativa" e outros. O professor deixa de ser o único "transmissor" do conhecimento, já que todos os envolvidos o possuem também, assim, o resultado refletirá em produção de questionamentos e oposições de ideias, o que gera um grau de respeitabilidade entre os agentes envolvidos, ou seja, o aprendizado não ocorre somente a partir de uma leitura, mas também com base em confluências de conceitos criados pela experimentação da coletividade.

Dessa forma, observa-se que 0 conceito de pragmatismo admite, substancialmente, o trabalho em questão, já que temos o ensino de música envolto em um processo propulsor para o encadeamento de experiências. N esse contexto, o papel da escola na sociedade é proporcionar um ambiente não apenas de adequação das pessoas em um lugar no mundo, mas sim um lugar que contribua para a superação dessa realidade: uma formação transformadora.

\section{Ensino de música, criatividade e experiência}

Entende-se que a música é uma ferramenta poderosa e ela possui diversos formatos para a sua vivência. Seja na forma lúdica, teórica, prática ou preceptiva, a música sempre penetra e mexe com os anseios das pessoas, conforme afirma Brito (2003, p.187) a respeito da apreciação e da escuta musical "faz parte do processo de perceber, sentir, relacionar, pensar, comunicar-se" (apud BEYER, 2012, p.29). A aula de música na escola, quase sempre, apresenta-se como ferramenta disparadora para a construção e criação, contribuindo para a organização das capacidades, habilidades e aptidões. Também é possível refletir que o ensino de música promove no educando instrumento motivador para 0 processo criativo, possibilitando experiências e 
oportunidades para expressar seus sentimentos e agir em atividades prazerosas e lúdicas. Isso reforça a importância da expressão na educação musical. D ewey confere:

[...] a expressão do eu em e através de um meio, constituindo a obra de arte, é em si uma interação prolongada de algo proveniente do eu com as condições objetivas, processo em que ambos adquirem uma forma e uma ordem que de início não possuem. (D EW EY, 2010, p. 153)

Podemos verificar a relação das citações acima a partir de dois exemplos de atividades musicais abaixo relacionados.

\section{EXEM PLO 1 - ATIVIDADE "VIDA BOA NA LAGOA"}

A atividade procurou desenvolver três elementos consideráveis: o canto, a rítmica e a criatividade. Em um primeiro momento, foi ensinada a canção "Vida de Sapo". Uma simples melodia que foi trabalhada em duas vozes. A pesar de haver diversas canções que falam de sapo, esta, utilizada na atividade, mostrou-se desconhecida para crianças. E sse é o tipo de dinâmica musical que, quando é feita uma vez, a sua lembrança acontecerá inúmeras vezes, principalmente, devido ao fato do texto da canção conter rimas: boa, lagoa; sapo e papo. D epois de cantar, o próximo passo foi pular como um sapo no ritmo da música. $0 \mathrm{~s}$ alunos foram orientados a saltarem no mesmo andamento da melodia, - 0 que para al guns pareceu ser bem complicado.

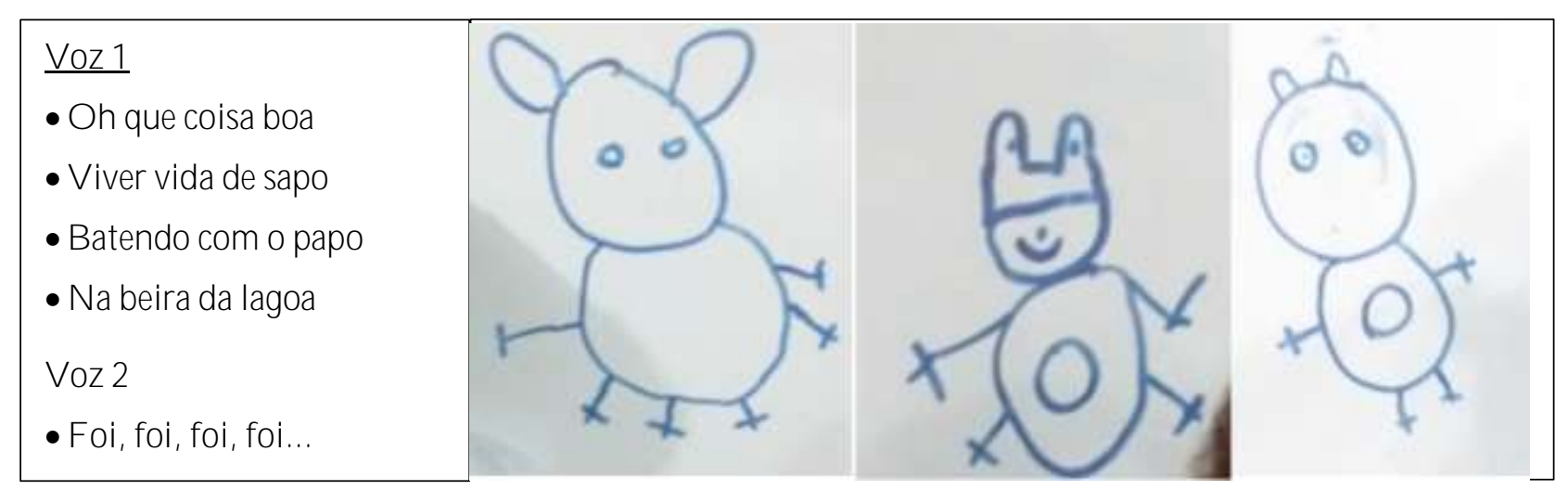

I magem 1: E xemplo de expressão e criatividade a partir de desenhos dos sapos realizados por crianças

Fonte: do autor 
Para desenvolver aspectos de criação, após ter cantado a canção, pedimos que cada criança fizesse um desenho. N essa última fase da atividade, dava-se ao aluno a possibilidade de desencadear um processo criativo por meio do imaginário e resultante da espontaneidade de cada um. A criança se deslocava no quadro e desenhava o seu próprio sapo, deliberando uma experiência intelectiva. A criança construiu um momento próprio para se colocar e, consequentemente, inserir a sua criação. A o criarem seus próprios desenhos, o cognitivo foi estimulado e a memória foi ampliada.

Assim, vemos que o processo de criação, por meio do ensino de música aguçou 0 cognitivo do mundo infantil, auxiliado pelos cinco sentidos, o que segundo $M$ arques são mensagei ros que refletem no desejo de aprender:

\begin{abstract}
A inteligência da criança quando entra no mundo vem acompanhada de cinco mensageiros: ver, ouvir, saborear, pegar, cheirar. A traídos pelo desejo de aprender, a inteligência e seus mensageiros que se lançam pelo mundo afora. (M A RQ UES, 2009, p.28).
\end{abstract}

Devemos também considerar a escola como local propício para 0 desenvolvimento das atividades. Segundo Vygotsky, a experiência e a sala de aula são atuantes correlatas com o desenvolvimento e a formação de conceitos pela criança:

[...] com base na simples observação, sabemos que os conceitos se formam e se desenvolvem sob condições internas e externas totalmente diferentes, dependendo do fato de se originarem do aprendizado em sala de aula ou da experiência pessoal da criança. (VY G O T SKY, 2005, p.108).

A juizamos ainda que a escola é o melhor caminho para dar início a esse processo, repleto de formas criativos, que disparam experiências estéticas que manifestem momentos expressivos de valores culturais com significados próprios e multiplicadores. N esse contexto, D ewey destaca:

A experiência estética é uma manifestação, um registro e uma celebração da vida de uma civilização, um meio para promover seu desenvolvimento, e também o juízo supremo sobre a qualidade dessa civilização. Isso porque, embora ela seja produzida e desfrutada por indivíduos, esses indivíduos são como são, no conteúdo de sua experiência, por causas das culturas de que participam. (DEWEY, 2010, p 551). 
A ssim, refletimos que essa última ação da aula, exposta pelo exem plo, considerou intensamente os processos criativos. Ponderamos que essas experiências devem ser promovidas e divulgadas para que o resultado reflita diretamente nas práticas educacionais. 0 utrossim, temos que 0 ensino de música promove uma experiência real e possibilita o desenvolvimento de sentimento de confiança em nossa capacidade inteligível, estética, de inter-relação pessoal e inserção social. A lém do mais, proporciona a ampliação da sensibilidade, o desenvolvimento da percepção, da reflexão e da imaginação numa busca constante da criação.

\section{EXEM PLO 2 - "ATIVIDADE PASSEANDO NA FAZENDA"}

$\mathrm{N}$ esta outra atividade, 0 elemento fundamental trabalhado foi 0 canto. 0 professor contou uma história de qualquer fazenda repleta de animais e quando caminhava pelos diferentes lugares se deparou com cada um deles e pergunta: qual é o som que você produz. Segue a letra:

\section{F ui na fazenda passear,}

\section{Lá eu encontrei uns animais}

\section{C antem, cantem, cantem animais, oi oi oi oi oi!}

\section{E como é que elefaz?}

Cada criança, usando no rosto uma máscara que representava um animal diferente, respondia cantando em voz solo uma reprodução mais semelhante daquela que faria o animal referente a máscara utilizada. I mportante ressaltar que as orientações direcionavam para uma proximidade à tonalidade e à métrica.

N esse contexto, T eixeira afirma que:

O canto é um veículo de comunicação e de expressividade, que aperfeiçoado e praticado transmite uma mensagem ao público. A lém disso, podemos considerá-lo de duas formas: como sendo um instrumento musical, único em cada pessoa - capaz de produzir sons definidos, reproduzir melodias, além de uma ampla gama de possibilidades timbrísticas -, e como sendo um instrumento para a 
aprendizagem musical - sua prática está ligada ao ensino, como recurso para este fim. (TEIXEIRA, 2009, p. 30)

D e tal modo, desenvolver o canto em música reflete em mais um procedimento que envolve 0 vasto conteúdo da educação musical. Vemos também nesse exercício, a tentativa de que 0 aluno consiga, mesmo que de forma subjetiva, perceber as mudanças sonoras ocorridas pelos diferentes timbres, contribuindo para a promoção de articulações entre as formas sonoras.

Assim, levando em consideração que por meio de brincadeiras musicais que envolvem o amplo universo do contexto do ensino de música, principalmente, aqueles relacionados com elementos fundamentais do extenso teor para a aprendizagem musical, essas atividades formam subsídios para processos criativos.

É importante salientar que a concepção de E ducação M usical aqui pensada é a mesma alinhada com a da professora M aura Penna, em que a musicalização mostra-se como processo educacional que engloba os instrumentos de percepção e pensamento imprescindível para a compreensão da linguagem musical, e que faz parte do conjunto de elementos próprios da E ducação M usical (PE N N A , 2008).

\section{Uma experiência em ambiente escolar}

Temos a escola como um ambiente favorável para refletir e desenvolver dinâmicas causadoras de efetivas experiências. 0 ensino de música como forma criativa deve ser refletida e construída a partir desse contexto.

[...] a escola como ponto de partida torna-se uma questão teóricometodológica que possibilita investir de maneira inovadora e que fornece condições de incluir toda uma série de novos personagens. (A pud FERNANDES, 2009, p.61).

0 transcorrer desse percurso que acontece na sala de aula, permite, também, vivenciar o processo criativo por meio do ensino de música.

Igualmente, encontrar na aula de música espaço envolvente para executar as atividades musicais que resultam no brincar, é promover novos caminhos metodológicos para o ensino de música, que são favoráveis à aprendizagem escolar, provocadoras de 
experiências idiossincráticas, ativas e estéticas. A inda sobre a aprendizagem musical em ambiente escolar, L oureiro destaca:

Reconhecer os valores atribuídos à música pelos alunos deve partir do próprio cotidiano escolar, pois assim, numa ação conjunta, o professor pode superar a reprodução de ideias, normas e valores, dos modelos enraizados nos discursos acadêmicos e tentar uma aproximação com a música que os alunos levam para dentro da sala, contextualizando-a de acordo com a sua realidade, ao mesmo tempo que aos alunos cabe viver com mais intensidade a música, enriquecendo, cada vez mais, o seu universo musical. (L O URE IRO, 2010, p.116).

Devemos também, considerar a função do professor como incentivador de iniciativas que desenvolvam o estímulo do brincar. V emos na imagem abaixo, retirada de uma pesquisa realizada em âmbito nacional, que, o brincar, quando estimulado, promove o desenvolvimento da criatividade com maior amplitude e eficácia, do que quando promovido de forma espontânea.

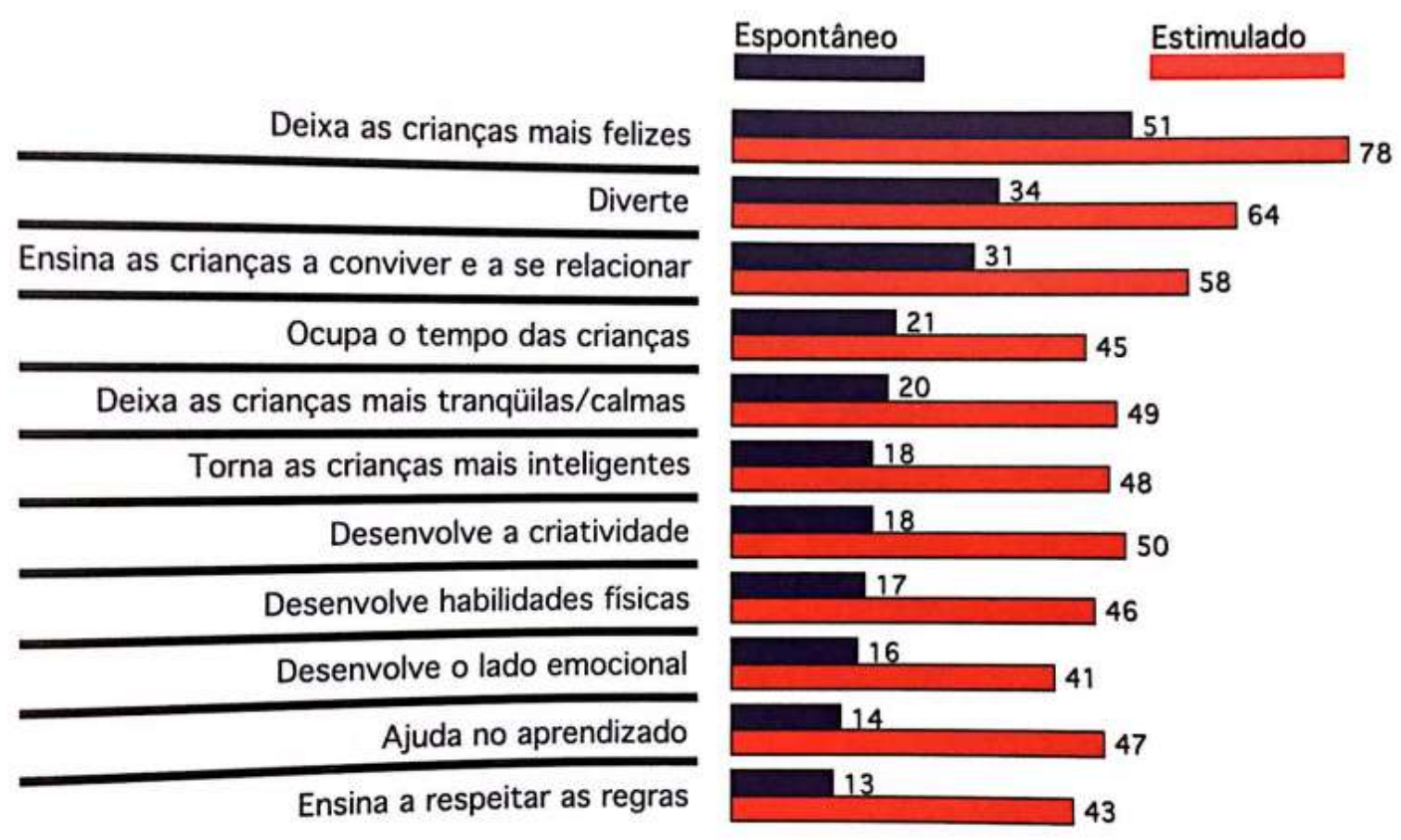

Imagem 2: $O$ s benefícios do Brincar

Fonte: CARNEIRO, M aria A. B.; DODGE, Janine J. A DESCOBERTA DO BRINCAR 
$N$ esse aspecto, a escola deveria incentivar os processos criativos com intuito de construir experiências ativas. $\mathrm{C}$ abe ao professor de música ser uma peça importante dessa engrenagem, pois assim, será promovido o desenvolvimento da criança, assim confere Z agonel:

\footnotetext{
A criação musical deve ser o ponto principal do processo de ensinoaprendizagem ou de prática musical. $\mathrm{M}$ ais do que 0 aprendizado ou a execução perfeita de exercícios e músicas, o importante é o propiciar, por meio da musicalização, modificações internas que levem ao crescimento do indivíduo. (ZA G O N E L, 2012, p.17)
}

Portanto, criar, em música, refere-se a todo procedimento que envolva o inventar musical, tecnicamente o que se relaciona ao termo improvisação musical. As brincadeiras musicais são ferramentas que promovem momentos de criação, sem limites, sem empecilhos e sem rigidez, estimulando a criação musical em professores e alunos, principalmente, em ambiente escolar que, ao vivenciar as atividades musicais que conduziram o aluno às brincadeiras, normalmente, resultará em um aprendizado musical dinâmico com elementos criativos respeitáveis, certamente, uma "experiência intelectual".

No entanto, D ewey difere experiência comum cotidiana e passiva, de experiência intelectual. Uma experiência comum "Com certeza, trata-se de uma atividade suficientemente 'prática', [...] com a consistência permitida pelas circunstâncias". (DEWEY, 2010, p.115). Porém, quando avaliamos uma experiência intelectual, percebemos uma ação que agrega elementos que conduzem a questões qualitativas que perpassam a experiência comum. Ela é formada pelas pretensões dos resultados finais; pelas inclinações encontradas durante a trajetória; pelas condições positivas ou negativas formadoras; pelos sentimentos sensíveis atribuídos no caminho. Essa é a experiência ansiada para o espaço escolar vivenciadas não somente pelo professor, mas também pelo aluno, onde esses personagens se encontram em seus processos criativos. Percebemos que a partir do processo de troca de experiências serão aguçados os principais sentidos da vida, sendo isso, de suma importância. Segundo Penna (2008, p.98) "Sem dúvida, o diálogo e a troca de experiências são indicações viáveis para o trabalho pedagógico em arte e em educação musical".

A inda, no que se refere à experiência $D$ ewey destaca que: 
A experiência, na medida em que é experiência, consiste na acentuação da vitalidade. Em vez de significar um encerrar-se em sentimentos e sensações privados, significa uma troca ativa e alerta com o mundo; em seu auge, significa uma interpenetração completa entre o eu e o mundo dos objetos e acontecimentos. (DEW EY, 2010, p.83).

O utrossim, ao propor uma reflexão com as pessoas envolvidas no processo de ensino aprendizagem, ancorada em seus conhecimentos e experiências, poderemos melhor compreender o processo de criação que aflora no ensino de música e em ambiente escolar.

\section{Considerações Finais}

Levando em consideração que por meio do ensino de música, caminhos significativos para uma aprendizagem efetiva são construídos, da mesma forma que, resultados positivos são alcançados em aulas de música, principalmente, nos percursos que dizem respeito ao aproveitamento na capacidade delas em sala de aula, é possível afirmar que toda essa experimentação é válida e eficaz.

É irrefutável que a música preenche as lacunas e os anseios das crianças. A criação promovida a partir do ensino de música reflete em um momento crucial, incidindo de forma contundente na sua experiência, outrossim, contribui para a valorização do ensino de música. Certamente, ponderamos que essa arte precisa ser valorizada. Dewey afirma que "a continuidade da cultura, na passagem de uma civilização para outra e dentro da própria cultura, é mais condicionada pela arte do que por qualquer outra coisa. (D EW EY, 2010, p.552).

A criatividade que frui da naturalidade promovida pela aula de música, permite a deliberação de elementos fundamentais para o desenvolvimento infantil que apoiam e colaboram, dando equilíbrio para o processo de aprendizagem, como também, para uma experiência musical ativa.

0 processo criativo, resultante da espontaneidade, possibilitada pelo ensino de música aflora, seleciona, comunica, relaciona, socializa, qualifica e organiza a vida da criança. Esses elementos criam aspectos apoiadores e auxiliadores, funcionando como uma balança para que tenhamos uma aprendizagem e uma experiência musical ativa. 
Concluindo, refletimos que a aula de música permite condições para a criação que promove uma experiência intelectual e fundamental para a vida da criança, transformando a vida do aluno e do professor.

\section{Referências}

BEYER, E. e KE BA CH , P. Pedagogia M usical. 2. ed. Porto A legre: M ediação 2012.

BITTEN C OURT, Circe. Disciplinas escolares: história e pesquisa. In: OLIVEIRA, $M$ arcus A. T. e RA N ZI, Serlei M . F. (O rgs.) H istória das disci plinas escolares no B rasil: contribuições para o debate. B ragança Paulista: E D USF , 2003, p. 9-38

CARNEIRO, M aria A. B.; DODGE, Janine J. A D escoberta do Brincar. São Paulo: M elhoramentos/Boa Companhia, 2007.

CHIZZOTTI, Antonio. Pesquisa em Ciências Humanas e Sodais. 10. ed. São Paulo: Cortez, 2009.

DEW EY, John. Arte como Experiência. (T radução de V era Ribeiro) São Paulo: M artins Fontes, 2010.

FE R N A N D E S, I veta M . B. Á vila. M úsica na escola: desafios e perspectivas na formação contínua de educadores da rede pública. 2009. 349 f. T ese (D outorado em E ducação), Universidade de São Paulo, Faculdade de E ducação, São Paulo, 2009.

FO N SE CA , J. J. S. M etodologia da pesquisa científica. Fortaleza: U E C , 2002. A postila.

LOUREIRO, Alícia M. Almeida. 0 ensino de música na escola fundamental. 7. ed. Campinas, SP. Papirus, 2010.

M ARQUES, Francisco. M uitas coisas, poucas palavras: A oficina do professor Comênio e a arte de ensinar e aprender. São Paulo: Peirópolis, 2009. (A companha 1 C D .) 
PE N N A , M . M úsica(s) e seu ensino. Porto A legre: Sulina, 2008.

SCHAFER, M urray R. 0 Ouvido Pensante Tradução de Maria Trench de 0 . Fonterrada. 2. ed. São Paulo: U N E SP, 2011.

SW A N W ICK, K eith. E nsinando M úsica M usicalmente. São Paulo: M oderna, 2010.

VYG OTSKY, L. S. Pensamento e Linguagem. T radução de Jeferson L uiz C amargo; Revisão T écnica de José C ipolla N eto.3. ed. São Paulo: M artins Fontes, 2005.

WESTBROOK, Robert B.; TEIXEIRA, A nísio. John D ewey. (E ducadores). José E ustáquio R omão, V erone $L$ ane R odrigues (org.). Recife: Fundação Joaquim $N$ abuco, 2010.

ZA G ON EL , B. Brincando com música na sala de aula: jogos de criação musical usando a voz, o corpo e o movimento. C uritiba: I bpex, 2011. (Série E ducação M usical). 